\title{
Age estimation by pulp/tooth area ratio in a Korean sample on digital panoramic radiographs
}

\author{
Byung-Yoon Roh ${ }^{1,2}$, Chang-Gyum Kim ${ }^{3}$, Sang-Seob Lee ${ }^{4}$, Won-Joon Lee ${ }^{5}$, Yo-Seob Seo ${ }^{6}$, Ji-Won Ryu ${ }^{7}$, Jong-Mo Ahn ${ }^{7}$, and \\ Chang-Lyuk Yoon ${ }^{7 *}$
}

${ }^{1}$ Medical Examiner, Forensic Medicine Division, National Forensic Service Gwangju Institute, Jangseong-gun, Republic of Korea

${ }^{2}$ Postgraduate Student, Department of Oral Medicine, School of Dentistry, Chosun University, Gwangju, Republic of Korea

${ }^{3}$ Research Assistant, Section of Human Identification, Medical Examiner's Office, National Forensic Service, Wonju, Republic of Korea

${ }^{4}$ Medical Examiner, Section of Human Identification, Medical Examiner's Office, National Forensic Service, Wonju, Republic of Korea

${ }^{5}$ Medical Examiner, Section of Human Identification, Department of Forensic Medicine Investigation, National Forensic Service Seoul Institute, Seoul, Republic of Korea

${ }^{6}$ Professor, Department of Oral \& Maxillofacial Radiology, School of Dentistry, Chosun University, Gwangju, Republic of Korea

${ }^{7}$ Professor, Department of Oral Medicine, School of Dentistry, Chosun University, Gwangju, Republic of Korea

Age estimation based on the change in the size of the pulp due to secondary dentin deposition can be conducted non-invasively using radiographic photographs. Among these methods, age estimation using the pulp/tooth area ratio is highly accurate. The present study was conducted to apply this method using the panoramic radiographs of a Korean sample population and to evaluate its applicability in the Korean population. The study was conducted using panoramic radiographic images of 349 Koreans aged 20-79 years. The pulp/ tooth area ratio was calculated by measuring the area of the pulp and tooth. Teeth with a single canal, such as maxillary central incisor, lateral incisor, canine, and mandibular canine, were selected. Correlations between this ratio and age were calculated and regression formulas were derived. Age and pulp/tooth area ratio showed relatively low correlations compared with other studies. In particular, men showed lower correlations than women, and upper teeth showed a higher correlation than lower teeth. The regression formulas derived in this study also showed higher errors than those reported in other studies. Age estimation using pulp/tooth area ratio in a Korean using digital panoramic radiographs showed larger errors when compared with previous studies. Morphological diversity of tooth and pulp, indistinct anatomical details in panoramic radiograph, reduction in crown size due to attrition, and ethnic differences are believed to have affected the results.

Key Words: Age estimation by teeth, Panoramic radiography, Secondary dentin

(c) This is an open-access article distributed under the terms of the Creative Commons Attribution Non-Commercial License (http://creativecommons.org/licenses/by-nc/4.0) which permits unrestricted noncommercial use, distribution, and reproduction in any medium, provided the original work is properly cited.

\section{Introduction}

법치의학에서 방사선 사진을 이용한 연령추정법은 다양하게 활용되고 있다. 어린이, 유소년기에는 방사선 사진상에서 치아
의 발육 단계를 평가하여 연령을 추정하는 방법들이 많이 소개 되었으며 연구되고 있다. 한편 성인에서는 치수강크기 감소를 이용하여 연령추정이 이루어지는데, 특히 발치 등이 필요한 다 른 법치의학적 연령추정법들에 비침습적으로 이용될 수 있다는

Received September 18, 2020; Revised November 2, 2020; Accepted November 7, 2020

*Corresponding author: Chang-Lyuk Yoon, Department of Oral Medicine, School of Dentistry, Chosun University, 303 Pilmun-daero, Donggu, Gwangju 61452, Republic of Korea.

Tel: +82-62-220-3890, Fax: +82-62-232-7776, E-mail: clyoon09@gmail.com

Copyright $\odot$ 2020, Oral Biology Research Institute 
장점이 있다[1].

성인의 연령추정에서 방사선사진을 이용한 대표적인 방법으 로는 Kvaal 등[2]이 제안한 치근단 방사선사진상에서 치수와 치 아의 길이와 넓이를 측정하여 연령을 추정하는 방법이 있다. 이 방법은 상악중절치, 측절치, 제 2 소구치, 하악 측절치, 견치, 제 1 소구치의 치수와 치아의 길이와 폭을 계측하여 이를 통한 연 령추정식을 도출하였으며 비교적 높은 정확도를 보고하고 있 다. 이 방법을 파노라마 방사선사진이나 computed tomograph (CT)에 적용한 여러 연구들이 또한 수행되었으며, 다양한 결과 를 보고하고 있다[3-8].

치수와 치아의 면적비를 이용하여 연령을 추정하는 방법도 보고되었다. Cameriere 등[9-11]의 연구가 대표적인 연구로, 파노라마 방사선사진, 치근단 방사선사진 모두에서 시행되었으 며, 매우 높은 정확성을 보고하고 있다[12].

또한 근래에는 CT상에서 치수와 치아의 부피비를 이용한 연 구들도 많이 시행되고 있는데, 다양한 three-dimensional 이미 지 분석 소프트웨어를 이용하여 치수와 치아의 부피를 측정하 여 연령과의 상관관계를 분석하고 있고, 다양한 결과를 보고하 고 있다[13-15].

이 외에도 방사선사진상에서 치수와 치아에 관한 다양한 계 측점들과 지표들을 이용한 연령추정법들이 연구되고 소개되고 있다[16,17].

이번 연구는 한국인의 파노라마방사선사진상의 치수/치아 의 면적비(pulp/tooth area ratio)를 이용한 연령추정법의 적용 가능성을 평가하기 위하여 시행되었다. 치수와 치아의 면적비 를 이용한 연령추정법을 한국인에게 적용하였을 때, 기존 문헌 들에서 보고되는 것만큼 높은 상관관계를 나타내는지 확인해보 고, 본 연구의 데이터를 바탕으로 연령추정 회귀식을 구하여 보 았다.

\section{Materials and Methods}

이번 연구는 조선대학교 치과병원에 2017년부터 2018년까 지 방문환 환자의 파노라마 방사선사진을 이용하여 후향적으

Table 1. Age and sex distribution of the subjects

\begin{tabular}{cccc}
\hline Age $(\mathbf{y})$ & Male & Female & Total \\
\hline $20-29$ & 27 & 30 & 57 \\
$30-39$ & 27 & 30 & 57 \\
$40-49$ & 30 & 30 & 60 \\
$50-59$ & 30 & 27 & 57 \\
$60-69$ & 30 & 30 & 60 \\
$70-79$ & 29 & 29 & 58 \\
Total & 173 & 176 & 349 \\
\hline
\end{tabular}

로 이루어졌다. 환자 정보는 익명으로 처리되었고, 나이, 성별 을 제외한 정보는 획득되지 않았다. 이 연구는 조선대학교 치과 병원 기관생명윤리위원회의 승인을 받았다(IRB no. CUDHIRB 1802002). 조사 대상자의 연령과 성별 분포는 다음과 같다 (Table 1).

치아의 선택은 단일근관을 주로 가지는 치아들을 선택하였 다. 상악중절치, 측절치, 송곳니, 하악 송곳니의 근관형태는 대 부분 단일근관으로 보고되고 있어서[18-20], 이 4 개 치아를 대 상으로 계측이 이루어졌다. 치아우식증이 있거나, rotation된 치 아, 보철치료 등의 치료가 시행된 치아가 포함된 경우는 제외하 였다.

방사선사진은 PiViewSTAR PACS workstation (INFINITT Healthcare Co., Ltd., Seoul, Korea)를 이용하여 JPG 형태로 변환하였고, Adobe Photoshop CS5 (Adobe System Inc., San Jose, CA, USA)를 이용하여 치수와 치아의 면적을 계측하였다. 자석올가미도구를 이용하여 치아, 치수의 경계를 특정하였고, 면적 크기를 pixel로 측정하였다.

계측의 신뢰도를 확인하기 위하여 위하여 20개의 파노라마 방사선사진에 대해서 다른 관찰자가 치수와 치아 면적을 계측 하였고, 급내상관계수(intraclass correlation coefficient)를 도 출하여, 관찰자간 신뢰도를 분석하였다. 연령과 각 치아들의 면 적비, 상악 치아들의 평균값, 전체 치아들의 평균값에 대해서 상 관관계를 분석하였고, 이후 회귀식을 도출하여 보았다. 통계분 석에는 IBM SPSS statistics for Windows, Version 23.0 (IBM Co., Armonk, NY, USA)를 이용하였다.

\section{Results}

관찰자간에 치수와 치아의 면적 측정치에 대한 급내상관계수 는 0.994 (95\% confidence interval: 0.993-0.996)로 매우 높

Table 2. Pearson correlation coefficients between chronological age and pulp/tooth ratio

\begin{tabular}{clll}
\hline Tooth no. & Male & Female & Total \\
\hline $11 / 21$ & $-0.333^{\star *}$ & $-0.518^{\star *}$ & $-0.425^{\star *}$ \\
$12 / 22$ & $-0.287^{\star *}$ & $-0.492^{\star *}$ & $-0.395^{\star *}$ \\
$13 / 23$ & $-0.209^{\star *}$ & $-0.340^{\star *}$ & $-0.279^{\star *}$ \\
$33 / 43$ & $-0.172^{\star}$ & $-0.466^{\star *}$ & $-0.320^{\star *}$ \\
U & $-0.350^{\star *}$ & $-0.535^{\star *}$ & $-0.447^{\star *}$ \\
W & $-0.343^{\star *}$ & $-0.569^{* *}$ & $-0.461^{\star *}$ \\
\hline
\end{tabular}

$\mathrm{U}$, mean value of pulp/tooth area ratio of upper teeth $(\# 11 / 21,12 / 22$, and 13/23); W, mean value of pulp/tooth area ratio of all teeth (\#11/21, $12 / 22,13 / 23$, and $33 / 43$ ).

${ }^{a}$ FDI dental notation. ${ }^{*} p<0.05,{ }^{* *} p<0.01$. 
은 값을 나타내어 관측에 대한 높은 재현성을 보여주었다. 연령 과 치수와 치아의 면적비의 상관관계는 Table 2에 나타나있다. 치수/치아 면적비를 연구했던 기존의 연구들에 비해서 상관관 계는 낮은 값을 나타내었다. 상악치아는 하악치아에 비해서 높 은 상관관계를 보였으며, 특히 여성의 경우 남성에 비해서 높은 상관관계를 보였다. 남성에서 하악 견치는 가장 낮은 상관관계 를 나타내었다. 본 연구에서 계측된 치수와 치아의 면적비를 활 용하여 연령추정 회귀식을 도출한 결과는 Table 3에 나타나있 다. 해당 추정식의 오차는 14-16세를 나타내어 기존 연구에 비 하여 높게 나타났고, 결정계수도 다른 연구들에 비하여 낮은 값 을 나타내었다. 본 연구 자료의 분포와 회귀선은 Fig. 1에 나타 나 있다.

\section{Discussion}

본 연구에서 치수와 치아의 면적 비율을 이용한 연령추정법 은 큰 오차를 보였다. 이 연구 결과는 치수/치아 면적비를 연 구한 기존의 연구들과 많은 차이를 나타내고 있다. 기존의 치 수와 치아 비율을 이용한 연령추정식 연구들 중 Camerier 등 $[9,21,22]$ 의 연구는 높은 정확도를 보고하고 있다. 이후 다양한 인종에 적용하였을 경우에도 높은 정확도를 나타냈으며, 파노 라마 방사선사진상에서 해당 방법을 적용하였을 때도 비교적 높은 결과를 보였다[10,11,23,24].
본 연구에서 나타난 높은 오차는 여러가지 요인에서 기인할 수 있다. 파노라마 방사선사진상에서의 연구도 본 결과에 영향 을 미쳤을 수 있다. 파노라마 방사선사진은 구강 내 방사선사진 에 비해서 섬세한 해부학적인상을 보여주지 못하는 것으로 알 려져 있고, 균등하지 못한 이미지의 확대, 이미지의 왜곡 등의 단점을 보인다[25]. 매년 침착되는 이차상아질의 양이 많지 않

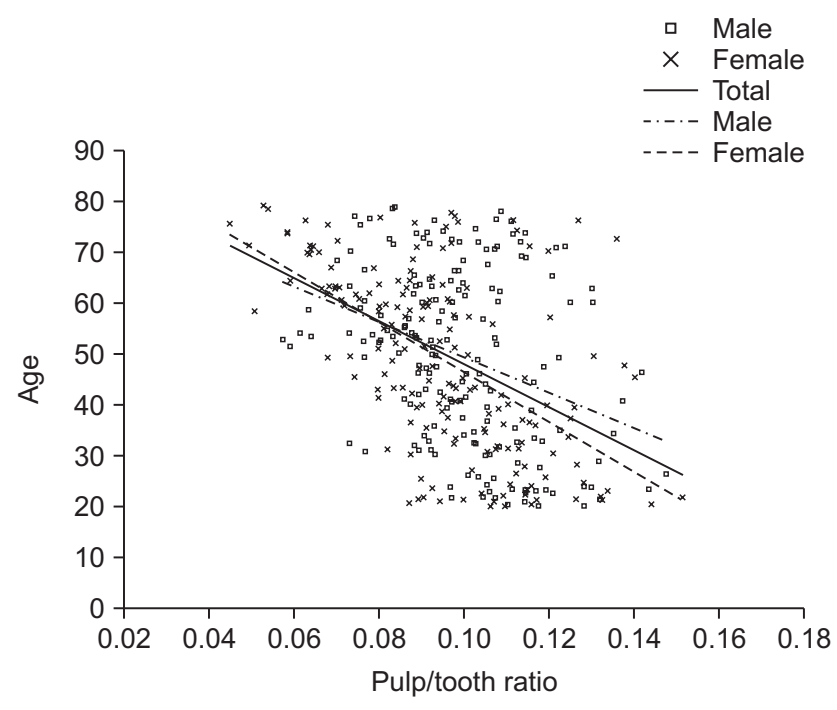

Fig. 1. Plot of chronologic age and regression line using mean value of pulp/tooth area ratio of all teeth (\#11/21, 12/22, 13/23, and 33/43).

Table 3. Regression formulae using PTR

\begin{tabular}{|c|c|c|c|c|}
\hline Tooth no. ${ }^{a}$ & Sex & Regression formulae & $\mathbf{r}^{2 \mathrm{~b}}$ & $\mathrm{SEE}^{\mathrm{c}}$ \\
\hline \multirow[t]{3}{*}{$11 / 21$} & Male & Age $=72.803-244.536 \times$ PTR & 0.106 & 16.215 \\
\hline & Female & Age $=85.048-391.367 \times$ PTR & 0.269 & 15.024 \\
\hline & Total & Age $=78.847-315.962 \times$ PTR & 0.181 & 15.691 \\
\hline \multirow[t]{3}{*}{$12 / 22$} & Male & Age $=70.278-206.728 \times$ PTR & 0.083 & 16.474 \\
\hline & Female & Age $=80.160-321.606 \times$ PTR & 0.242 & 15.298 \\
\hline & Total & Age $=75.828-269.394 \times$ PTR & 0.156 & 15.928 \\
\hline \multirow[t]{3}{*}{$13 / 23$} & Male & Age $=66.843-166.938 \times$ PTR & 0.044 & 16.818 \\
\hline & Female & Age $=70.349-215.322 \times$ PTR & 0.115 & 16.525 \\
\hline & Total & Age $=68.997-194.598 \times$ PTR & 0.078 & 16.648 \\
\hline \multirow[t]{3}{*}{$33 / 43$} & Male & Age $=62.303-127.531 \times$ PTR & 0.030 & 16.942 \\
\hline & Female & Age $=79.043-327.204 \times$ PTR & 0.217 & 15.543 \\
\hline & Total & Age $=71.073-227.389 \times$ PTR & 0.103 & 16.424 \\
\hline \multirow[t]{3}{*}{$\mathrm{U}$} & Male & Age $=82.299-328.947 \times$ PTR & 0.122 & 16.112 \\
\hline & Female & Age $=90.646-434.185 \times$ PTR & 0.286 & 14.849 \\
\hline & Total & Age $=87.013-386.177 \times$ PTR & 0.200 & 15.508 \\
\hline \multirow[t]{3}{*}{$\mathrm{W}$} & Male & Age $=84.204-347.920 \times \mathrm{PTR}$ & 0.117 & 16.158 \\
\hline & Female & Age $=95.575-491.079 \times$ PTR & 0.324 & 14.445 \\
\hline & Total & Age $=90.515-424.269 \times \mathrm{PTR}$ & 0.213 & 15.384 \\
\hline
\end{tabular}

PTR, pulp/tooth ratio; $U$, mean value of pulp/tooth ratio of \#11/21, 12/22, and 13/23; W, mean value of pulp/tooth ratio of all teeth (\#11/21, $12 / 22,13 / 23$, and $33 / 43)$.

${ }^{\mathrm{a}} \mathrm{FDI}$ dental notation, ${ }^{\mathrm{b}}$ Coefficient of determination, ${ }^{\mathrm{c}}$ Standard error of the estimate in years. 
으므로 이런 단점은 큰 오차를 유발할 수 있다. 평행촬영법을 이 용한 구강 내 방사선사진을 사용한 Kvaal 등[2]의 연령추정 연 구를 파노라마 방사선사진에서 적용해본 대부분의 연구들도 [5,6,26-28] Kvaal의 연구에 비해서 더 높은 오차를 보였다. 치 수와 치아의 면적비를 이용한 연구는 최초의 연구는 파노라마 방사선사진을 이용하였으나[9], 대부분은 구강 내 치근단 방사 선사진을 이용한 연구이며, 파노라마 방사선사진을 이용할 경 우 좀더 높은 오차를 나타내었다[11].

본 연구 결과는 치아와 치근의 형태학적인 다양성에 의하여 영향을 받았을 수도 있다. 치아와 치근의 크기와 형태는 매우 큰 다양성을 나타낸다. Leoni 등[29]의 연구에서와 같이 single root, single canal이어도 단순한 원추형의 형태를 보이는 것 은 아니고 root canal은 다양한 모습을 보인다. 비교적 높은 상 관관계를 보여준 Cameriere 등[30]의 연구에서 하악 전치부의 연령추정식의 오차가 비교적 높게 나타난 것은 하악 전치부의 canal의 다양성 때문일 수 있다. CT를 이용하여 치수와 치아의 volume 비율을 이용한 연령추정법이 높은 정확도를 나타내지 못하고, 낮은 상관관계를 보이는 경우도 있는데 이는 이런 형태 학적인 다양성에 기인한 것으로 생각할 수 있다[1,13,14,31].

한편 나이에 따른 교모의 증가도 본 연구결과에 영향을 미쳤 을 가능성이 있다. 증령에 따라서 치아의 교모는 증가하며 치관 의 크기를 감소시킨다. 몇몇 연구들은 치아의 교모를 이용한 연 령추정법을 보고하고 있으며, 한국인을 대상으로 한 연구에서 비교적 높은 상관관계를 보이고 있다[32,33]. 또한 한국인을 대 상으로 한 연구에서 남성의 교모가 여성에 비해서 더 많다는 점 은 남성이 여성에 비해 증령에 따른 치수/치아 면적의 상관관계 가 낮음을 설명할 수 있다[33]. Cameriere 등[30]은 2013년 연 구에서 이런 영향을 배제시키기 위하여 교모가 최소인 치아들 을 대상으로 연구를 수행하였다.

또, 인종에 따른 차이도 이와 같은 연구 결과에 영향을 미쳤을 것으로 보인다. 치아와 치수의 크기, 형태학적인 특징 등에서 인 종에 따른 차이가 나타나는 것이 보고되고 있다. 아시아인은 코 카시안인과 치아나 치수의 크기 및 형태의 차이가 있음을 보고 하고 있으며, 한국인의 치아는 코카시안에 비해 작은 것이 보고 되고 있다[34].

이번 연구는 파노라마 방사선 사진상에서 한국인에서 치아의 면적과 치수의 면적의 비를 이용한 연령추정법을 연구하여 보 았다. 기존의 연구들과 비교하여, 나이와 치수/치아 면적비는 상 관관계는 낮았고, 여성이 남성보다 높은 상관관계를 나타내었 다. 개개인 사이에 나타나는 치아와 치수의 형태학적인 다양성, 인종적 차이, 교모에 따른 치관크기의 감소, 파노라마 방사선사 진상의 왜곡 등의 영향으로 인하여 낮은 상관관계가 나타난 것 으로 생각된다. 해당 방법의 적용 가능성에 대하여 추후 더 많은
연구가 필요할 것으로 생각된다.

\section{Acknowledgements}

This study was supported by National Forensic Service Clinical Research Fund.

\section{Conflicts of Interest}

The authors declare that they have no competing interests.

\section{ORCID}

\author{
Byung-Yoon Roh \\ https://orcid.org/0000-0003-1703-3610 \\ Chang-Gyum Kim \\ https://orcid.org/0000-0003-3171-4236 \\ Sang-Seob Lee \\ https://orcid.org/0000-0002-0171-561X \\ Won-Joon Lee \\ https://orcid.org/0000-0002-2571-9201 \\ Yo-Seob Seo \\ https://orcid.org/0000-0003-1804-5648 \\ Ji-Won Ryu \\ https://orcid.org/0000-0002-5586-8195 \\ Jong-Mo Ahn \\ https://orcid.org/0000-0002-3615-3688 \\ Chang-Lyuk Yoon \\ https://orcid.org/0000-0003-4805-2355
}

\section{References}

1. Marroquin TY, Karkhanis S, Kvaal SI, Vasudavan S, Kruger E, Tennant M. Age estimation in adults by dental imaging assessment systematic review. Forensic Sci Int 2017;275:203-211. doi: 10.1016/j.forsciint.2017.03.007.

2. Kvaal SI, Kolltveit KM, Thomsen IO, Solheim T. Age estimation of adults from dental radiographs. Forensic Sci Int 1995;74:175-185. doi: 10.1016/0379-0738(95)01760-g.

3. Paewinsky E, Pfeiffer H, Brinkmann B. Quantification of secondary dentine formation from orthopantomograms--a contribution to forensic age estimation methods in adults. Int J Legal Med 2005;119:27-30. doi: 10.1007/s00414-0040492-X.

4. Bosmans N, Ann P, Aly M, Willems G. The application of 
Kvaal's dental age calculation technique on panoramic dental radiographs. Forensic Sci Int 2005;153:208-212. doi: 10.1016/j.forsciint.2004.08.017.

5. Meinl A, Tangl S, Pernicka E, Fenes C, Watzek G. On the applicability of secondary dentin formation to radiological age estimation in young adults. J Forensic Sci 2007;52:438441. doi: 10.1111/j.1556-4029.2006.00377.x.

6. Landa MI, Garamendi PM, Botella MC, Alemán I. Application of the method of Kvaal et al. to digital orthopantomograms. Int J Legal Med 2009;123:123-128. doi: 10.1007/ s00414-008-0268-9.

7. Marroquin Penaloza TY, Karkhanis S, Kvaal SI, Nurul F, Kanagasingam S, Franklin D, Vasudavan S, Kruger E, Tennant M. Application of the Kvaal method for adult dental age estimation using Cone Beam Computed Tomography (CBCT). J Forensic Leg Med 2016;44:178-182. doi: 10.1016/j.jflm.2016.10.013.

8. Hisham S, Abdullah N, Noor MHM, Franklin D. Quantification of secondary dentin formation based on the analysis of MDCT scans and dental OPGs in a contemporary Malaysian population. Leg Med (Tokyo) 2019;36:59-66. doi: 10.1016/ j.legalmed.2018.11.004.

9. Cameriere R, Ferrante L, Cingolani M. Variations in pulp/ tooth area ratio as an indicator of age: a preliminary study. J Forensic Sci 2004;49:317-319. doi: 10.1520/JFS2003259.

10. Cameriere R, Cunha E, Sassaroli E, Nuzzolese E, Ferrante L. Age estimation by pulp/tooth area ratio in canines: study of a Portuguese sample to test Cameriere's method. Forensic Sci Int 2009;193:128.e1-128.e6. doi: 10.1016/ j.forsciint.2009.09.011.

11. Cameriere R, De Luca S, Alemán I, Ferrante L, Cingolani M. Age estimation by pulp/tooth ratio in lower premolars by orthopantomography. Forensic Sci Int 2012;214:105-112. doi: 10.1016/j.forsciint.2011.07.028.

12. Azevedo AC, Michel-Crosato E, Biazevic MG, Galić I, Merelli V, De Luca S, Cameriere R. Accuracy and reliability of pulp/tooth area ratio in upper canines by peri-apical Xrays. Leg Med (Tokyo) 2014;16:337-343. doi: 10.1016/ j.legalmed.2014.07.002.

13. Sakuma A, Saitoh H, Suzuki Y, Makino Y, Inokuchi G, Hayakawa M, Yajima D, Iwase H. Age estimation based on pulp cavity to tooth volume ratio using postmortem computed tomography images. J Forensic Sci 2013;58:15311535. doi: 10.1111/1556-4029.12175.

14. De Angelis D, Gaudio D, Guercini N, Cipriani F, Gibelli D, Caputi S, Cattaneo C. Age estimation from canine volumes. Radiol Med 2015;120:731-736. doi: 10.1007/s11547-0150521-5.

15. Asami R, Aboshi H, Iwawaki A, Ohtaka Y, Odaka K, Abe S, Saka H. Age estimation based on the volume change in the maxillary premolar crown using micro CT. Leg Med (Tokyo) 2019;37:18-24. doi: 10.1016/j.legalmed.2018.12.001.

16. Jeon HM, Jeon JW, Kim SY, Jung KH, Ok SM, Jeong SH, Ahn
YW. An assessment of radiological age estimation method using mandibular first molars in Korean adults. Korean J Leg Med 2017;41:7-11. doi: 10.7580/kjlm.2017.41.1.7.

17. Jeon HM, Jang SM, Kim KH, Kim SY, Jung KH, Ok SM, Jeong SH, Ahn YW. Age estimation based on pulp chamber size of mandibular first molars from intraoral periapical radiographs in Korean. Korean J Leg Med 2018;42:56-61. doi: 10.7580/kjlm.2018.42.2.56.

18. Vertucci FJ. Root canal anatomy of the human permanent teeth. Oral Surg Oral Med Oral Pathol 1984;58:589-599. doi: 10.1016/0030-4220(84)90085-9.

19. Sert S, Bayirli GS. Evaluation of the root canal configurations of the mandibular and maxillary permanent teeth by gender in the Turkish population. J Endod 2004;30:391398. doi: 10.1097/00004770-200406000-00004.

20. Vertucci FJ. Root canal morphology and its relationship to endodontic procedures. Endod Top 2005;10:3-29. doi: 10.1111/j.1601-1546.2005.00129.x.

21. Cameriere R, Brogi G, Ferrante L, Mirtella D, Vultaggio C, Cingolani M, Fornaciari G. Reliability in age determination by pulp/tooth ratio in upper canines in skeletal remains. J Forensic Sci 2006;51:861-864. doi: 10.1111/j.15564029.2006.00159.x.

22. Cameriere R, Ferrante L, Belcastro MG, Bonfiglioli B, Rastelli E, Cingolani M. Age estimation by pulp/tooth ratio in canines by peri-apical X-rays. J Forensic Sci 2007;52:166170. doi: 10.1111/j.1556-4029.2006.00336.x.

23. Jeevan MB, Kale AD, Angadi PV, Hallikerimath S. Age estimation by pulp/tooth area ratio in canines: Cameriere's method assessed in an Indian sample using radiovisiography. Forensic Sci Int 2011;204:209.e1-209.e5. doi: 10.1016/j.forsciint.2010.08.017.

24. Zaher JF, Fawzy IA, Habib SR, Ali MM. Age estimation from pulp/tooth area ratio in maxillary incisors among Egyptians using dental radiographic images. J Forensic Leg Med 2011;18:62-65. doi: 10.1016/j.jflm.2010.12.004.

25. White SC, Pharoah MJ. Oral radiology: principles and interpretation. 6th ed. London: Elsevier Health Sciences; 2008.

26. Erbudak HÖ, Ozbek M, Uysal S, Karabulut E. Application of Kvaal et al.'s age estimation method to panoramic radiographs from Turkish individuals. Forensic Sci Int 2012;219:141-146. doi: 10.1016/j.forsciint.2011.12.012.

27. Roh BY, Lee WJ, Ryu JW, Ahn JM, Yoon CL, Lee SS. The application of the Kvaal method to estimate the age of live Korean subjects using digital panoramic radiographs. Int J Legal Med 2018;132:1161-1166. doi: 10.1007/s00414017-1762-8.

28. Hisham S, Abdullah N, Mohamad Noor MH, Franklin D. Quantification of secondary dentin formation using dental orthopantomographs in a contemporary Malaysian population. Australian J Forensic Sci 2019;51 Suppl 1:S180-S183. doi: 10.1080/00450618.2019.1569130.

29. Leoni GB, Versiani MA, Pécora JD, Damião de Sousa-Neto 
M. Micro-computed tomographic analysis of the root canal morphology of mandibular incisors. J Endod 2014;40:710716. doi: 10.1016/j.joen.2013.09.003.

30. Cameriere R, Cunha E, Wasterlain SN, De Luca S, Sassaroli E, Pagliara F, Nuzzolese E, Cingolani M, Ferrante L. Age estimation by pulp/tooth ratio in lateral and central incisors by peri-apical X-ray. J Forensic Leg Med 2013;20:530-536. doi: 10.1016/j.jflm.2013.02.012.

31. Star H, Thevissen P, Jacobs R, Fieuws S, Solheim T, Willems G. Human dental age estimation by calculation of pulp-tooth volume ratios yielded on clinically acquired cone beam computed tomography images of monora- dicular teeth. J Forensic Sci 2011;56 Suppl 1:S77-S82. doi: 10.1111/j.1556-4029.2010.01633.x.

32. Yun JI, Lee JY, Chung JW, Kho HS, Kim YK. Age estimation of Korean adults by occlusal tooth wear. J Forensic Sci 2007;52:678-683. doi: 10.1111/j.1556-4029.2007.00414.x.

33. Kim YK, Kho HS, Lee KH. Age estimation by occlusal tooth wear. J Forensic Sci 2000;45:303-309. doi: 10.1520/ JFS14683J.

34. Kim E, Fallahrastegar A, Hur YY, Jung IY, Kim S, Lee SJ. Difference in root canal length between Asians and Caucasians. Int Endod J 2005;38:149-151. doi: 10.1111/j.13652591.2004.00881.x. 